\title{
Promovendo o protagonismo juvenil por meio de blogs e outras redes sociais no Ensino de Biologia
}

\author{
Lucy Mirian Campos Tavares Nascimento, Instituto Federal de Goiás - IFG \\ lucycmb@gmail.com \\ Lenise Aparecida Martins Garcia, Universidade de Brasília - UnB \\ lenise.unb@gmail.com
}

\begin{abstract}
Resumo: Este artigo objetiva verificar se a produção, divulgação e uso de um blog de Biologia, feito por alunos do ensino médio de uma escola pública, contribui para o seu envolvimento e protagonismo, bem como discutir os fatores que colaboram ou restringem esses processos. Trata-se de parte da pesquisa de mestrado realizada sobre o uso de blogs e outras redes sociais: o aluno como produtor e divulgador. Nesse estudo pautamo-nos pelo estudo de caso, quanti-qualitativo, que usou três questionários mistos, entrevistas com grupo focal e comentários postados. Os dados tratados estatisticamente e por análise de conteúdo geraram as categorias: protagonismo, interatividade e concepção dos alunos sobre o blog. Constatou-se que o projeto proporcionou maior envolvimento e interação entre os alunos nativos digitais e a professora imigrante digital, colaborando para que o projeto se efetivasse, desencadeando nos alunos, maior interesse pelo ensino de Biologia e ações protagonistas diante dos desafios impostos.
\end{abstract}

Palavras-chave: blog, redes sociais, protagonismo, interação, nativo digital.

\section{Promoting youth proactive role through blog page and other social networks in the teaching of biologia}

Abstract: This paper aims to determine whether the production, dissemination and use of a Biology blog, made by high school students at a public school, contribute to their involvement and proactivity, as well as to discuss the factors that help or restrict these process. This is part of a Master's degree research about the use of blogs and others social networks: the student as criater and information spreader. This is a quantitative and qualitative case study which used three mixed questionnaires, focal group interviews and posted comments. Statistically processed data and content analysis generated three categories: proactivity, interaction and students ${ }^{\text {ee }}$ view on on the blog. It was observed that the project provided greater involvement and interaction among native digital students and digital immigrant teacher, collaborating for the project efficacy, triggering greater interest in students for Biology teaching and proactive roles before challenges.

Keywords: blog, social networks, proactivity, interation, digital native.

\section{Introdução}

Constata-se que a humanidade passa por inúmeras mudanças promovidas pela popularização das Novas Tecnologias da Informação, Comunicação e Expressão (NTICE) e também se percebe o desinteresse dos alunos em relação ao ensino de Biologia. Por outro lado nota-se o deslumbramento e fascínio desses mesmos alunos em relação aos aparatos tecnológicos e o entrosamento deles nas redes sociais.

Nesse cenário digital percebemos a naturalidade com a qual os jovens lidam com as tecnologias, sendo chamados por Prensky (2001) de nativos digitais. Tal termo se deve ao fato deles terem nascido em um mundo cercado por elas e desde cedo com elas 
interagirem. O que implica denominar aqueles que não nasceram nessa cultura, mas a compartilham, de imigrantes digitais.

Para Prensky (2001), a forma com a qual esses jovens compreendem e processam a informação mudou e isso se deve ao grande volume de interações envolvidas nos processos de aprendizagem de novas ferramentas tecnológicas, como videogames, hipertextos, celulares, softwares, etc. Em contrapartida, pais e educadores estão em constante processo de adaptação à inserção tecnológica e mesmo os mais abertos aos avanços tecnológicos e à comodidade por eles oferecida são e sempre serão imigrantes digitais e, como tal, carregarão por toda vida a própria formação cultural, processando as informações de forma diferente das novas gerações.

A interação entre as gerações de imigrantes e nativos digitais, em torno das ferramentas tecnológicas pode estreitar as relações entre os alunos e destes com os professores, como dito por Moran (2000): “educar é colaborar para que professores e alunos - nas escolas e organizações - transformem suas vidas em processos permanentes de aprendizagem [...]".

Em decorrência dessa nova realidade, a sociedade cada vez mais inserida no mundo digital, carece de mão de obra especializada, exigindo profissionais que sejam capazes de trabalhar em equipe, de se apropriar de novas informações, buscando o contínuo aprendizado, enfrentando os problemas diários e posicionando-se criticamente frente a eles na busca de soluções.

Nesse sentido Pierre Lévy destaca que as escolas e as universidades devem "ao menos dar-se por nova missão a de orientar os percursos individuais no saber e contribuir para o reconhecimento do conjunto de know-how das pessoas, inclusive os saberes não acadêmicos" (1999) numa perspectiva de construção da "inteligência coletiva" (Ibidem).

Tal entendimento envolve as redes sociais, independente de quais sejam elas e suas particularidades, todas compartilham os cinco pontos destacados por Recuero (2009). São eles: i) Consolidação das relações já existentes no mundo real e estabelecimento do espaço virtual para que os relacionamentos se mantenham por meio da conexão (interação e trocas); ii) As redes sociais são construídas pela forma como o usuário se apropria das ferramentas, que são as mesmas para diferentes grupos. De acordo com essa apropriação a rede terá o perfil do grupo; iii) As redes possibilitam a circulação da informação, que é filtrada pelos usuários e então divulgada. iv) São espaços de conversação e discussão; v) As redes podem desencadear movimentos de mobilização virtual e real, pois é a partir dos debates virtuais, que envolvem pessoas com interesses em comum, que essas ações podem se configurar no espaço real.

Considerando as características apresentadas percebemos que os blogs se enquadram no perfil de rede social. Eles podem ter um ou mais criadores/gerenciadores e diversificarem-se quanto ao propósito a que se destinam. Graças aos recursos de inserção de links e ferramentas de mídia (vídeos, fotos, espaços para comentários) um blog voltado ao fazer pedagógico pode explorar a leitura, a escrita e a capacidade de argumentação dos alunos.

Além disso, os usuários ao interagirem - compartilhando ideias, pensamentos e concepções a cerca de determinados assuntos - influenciam-se mutuamente (Primo, 2006). Nesse contexto, o professor deve atuar como mediador, estimulando os debates, instigando a produção dos alunos e estabelecendo contrapontos entre as mensagens.

Portanto, devemos considerar que um blog utilizado como prática educativa pode permitir aos alunos assumirem-se como produtores e divulgadores de informação, estabelecendo assim uma nova relação com o saber e colaborando para o fortalecimento do protagonismo juvenil. 
De acordo com Gomes da Costa (1996, p.90), o termo protagonismo juvenil é:

a participação do adolescente em atividade que extrapolam os âmbitos de seus interesses individuais e familiares e que podem ter como espaço a escola, os diversos âmbitos da vida comunitária; igrejas, clubes, associações e até mesmo a sociedade em sentido mais amplo, através de campanhas, movimentos e outras formas de mobilização que transcendem os limites de seu entorno sócio- comunitário.

Para nós, o protagonismo juvenil é compreendido como potencial a ser estimulado, que, se bem trabalhado, pode contribuir para a formação pessoal e social do educando, no sentido de capacitá-lo a aprender a aprender, postura essa fundamental ao enfrentamento dos desafios da sociedade científico-tecnológica, na qual ele está inserido.

Acreditando ser possível, mesmo para professores imigrantes digitais, utilizar as NTICE com propósito pedagógico e explorando seus recursos no ensino de Biologia é que durante o mestrado em Ensino de Ciências iniciamos nossa pesquisa. intitulada "Blogs e outras redes sociais: o aluno como produtor e divulgador" (Nascimento, 2012). Neste artigo apresentamos parte dessa pesquisa, na qual nos propomos a verificar se a produção, divulgação e uso de um blog educacional, por alunos do $2^{\circ}$ ano do ensino médio, voltado a temática Biologia, contribui para o seu envolvimento e protagonismo, bem como discutir os fatores que contribuem ou restringem esse processo.

\section{Materiais e Métodos}

Esta pesquisa foi realizada em uma escola pública federal de Brasília. Adotamos como instrumento investigativo o estudo de caso que buscou aliar as técnicas da pesquisa quanti-qualitativa e do grupo focal no sentido de melhor compreendermos os muitos "como" e "por quês" presentes no contexto dessa pesquisa.

A amostra foi formada por dois grupos de alunos, o grupo 1: composto por 8 alunos do $2^{\circ}$ ano do Ensino Médio, todos voluntários, que participaram das entrevistas de grupo focal e da elaboração e divulgação de um blog educacional voltado ao Ensino de Biologia e; o grupo 2: formado pelos alunos de quatro turmas também do $2^{\circ}$ ano, respondentes dos questionários 1,2 e 3 , não apresentando um $\mathrm{n}^{\circ}$ fixo em decorrência da falta de alguns alunos no dia em que os questionários foram respondidos. Contudo, todos os envolvidos tiveram acesso ao blog e responderam a três questionários mistos, contendo questões abertas e fechadas. Os dados tiveram tratamento estatístico e de análise de conteúdo (Bardin, 2011). Responderam ao questionário 1(Q1): 124 alunos, ao questionário 2 (Q2): 118 alunos e ao questionário 3 (Q3): 129 alunos.

\section{Resultados e Discussão}

De acordo com a proposição da análise de conteúdo definidas por Bardin (2011) os dados após analisados constituíram três categorias macro: i) o protagonismo juvenil; ii) a interatividade e; iii) as percepções dos alunos sobre o blog no Ensino de Biologia.

\subsection{Protagonismo juvenil}

Essa categoria buscou identificar se um projeto envolvendo as NTICE, mais especificamente a produção de um blog e uso de redes sociais, motivaria os estudantes a 
terem maior interesse pelo ensino de Biologia, a ponto de fazer com eles se engajassem num projeto de produção de um blog e assumissem uma postura protagonista.

Na tabela 1 podemos verificar como as respostas de uma das perguntas abertas dos questionários passados aos alunos foram organizadas segundo as orientações da análise de conteúdo (Bardin, 2011).

Tabela 1- Representação das declarações feitas pelos alunos sobre o questionamento:

"Você gostaria de participar da elaboração de um blog educacional?"

Tema Categoria Subcategoria Frequência (f) Porcentagem (\%)

\begin{tabular}{lcccc} 
& Participaria & \multicolumn{1}{c}{ NTICE } & 7 & 5,6 \\
\cline { 3 - 4 } & 41 & Aplicabilidade & 9 & 7,3 \\
\cline { 3 - 5 } & & Envolvimento & 8 & 6,5 \\
\cline { 3 - 5 } & & Disponibilidade & 6 & 4,8 \\
\cline { 3 - 5 } & & Não comentou & 11 & 11,3 \\
\cline { 3 - 5 } & Não & NTICE & 14 & 14,5 \\
\cline { 3 - 5 } & participaria & Envolvimento & 18 & 16,9 \\
\cline { 3 - 5 } & 83 & Disponibilidade & 21 & 24,2
\end{tabular}

Obs.: A frequência total corresponde ao $\mathrm{n}^{\mathrm{o}}$ de respondentes do Q1 -124 alunos.

Fonte: Nascimento (2012).

Com relação à pergunta descrita na tabela 1, dos 124 pesquisados, 41 responderam que gostariam de participar correspondendo a 33,1\% dos pesquisados. Contudo, ao marcarmos as reuniões em contraturno só aparecerem 16 alunos, sendo que passado o primeiro encontro restaram 8 alunos. Das justificativas descritas para participar, duas subcategorias se destacaram: o dinamismo proporcionado pelas mídias digitais e uma visão de aplicabilidade das informações, em benefício próprio e/ou extensivo a outras pessoas.

Destacamos alguns comentários:

- "Acho interessante a relação que poderíamos ter entre os conteúdos de Biologia e a internet".

- "Além de me ajudar a conhecer e fixar novos assuntos poderia ajudar outras pessoas a compreender esse mesmo conteúdo numa linguagem mais simples e objetiva do que em certos materiais didáticos”.

Mesmo entre os respondentes que disseram que não gostariam de participar, alguns reconheceram como válida a proposta, como constatamos nas frases abaixo:

- "Por não saber fazer um blog, apesar de concordar com a ideia de um blog”.

- "Porque não tenho muito tempo, mas se tivesse participaria".

Verificamos que o fator tempo e o excesso de atividades extraclasse foi descrito pelos alunos como um dos motivos para não participarem do projeto, encarando-o como mais uma atividade a ser cumprida. Isso nos leva a refletir sobre as atividades extraclasses e até que ponto elas auxiliam ou comprometem o ensino regular. E, mais, como podemos usufruir das NTICE no ensino tornando-as prazerosas sem que os jovens a rejeitem por acharem que se trata de mais atividade.

De acordo com Costa (2010), "participar para o adolescente é influir através de palavras e atitudes nos acontecimentos que afetam a sua vida e a de todos aqueles em relação aos quais assume uma posição de não diferença, uma atitude de valoração 
positiva". O que pode ser entendido como responsabilidade, a qual, muitos jovens não se sentem preparados a assumir. Como observamos na resposta:

- "Acho que não tenho tanta responsabilidade para isso."

Esse tipo de resposta foi discutido com os alunos do grupo focal que também pontuaram a responsabilidade como fator primordial para participar do projeto, como podemos verificar:

- "Primeiramente acho que a pessoa para vir aqui tem que ter muita responsabilidade, senão só querer fazer o blog de Biologia e ficar aqui sem fazer nada, só olhando o que os outros vão fazer. Porque quando ela vier para cá tem que ter em mente que vai ter responsabilidade assim maior. Acho que é isso."

Ao serem questionados se as pessoas hoje em dia têm medo de responsabilidade, responderam que sim e apresentaram vários argumentos, como:

- "É, responsabilidade tem que ter para tudo né? O problema é que depois que você coloca uma informação e se for o caso, essa informação se não for bem confirmada, depois alguém pode por a culpa em você”.

- "A responsabilidade tem que começar desde cedo. Desde cedo tem que ter responsabilidade. Pra mim, o blog tem que ter responsabilidade. Não tem que ter medo de errar, se não tentar não tem como acertar, fica parado. Se deu um passo, errou tudo bem, corrige-se esse erro. Senão não tem jeito”.

Outros argumentos apresentados foram à falta de domínio tecnológico e de envolvimento, levando-nos a questionar se eles realmente não têm domínio das ferramentas ou apenas não querem se envolver e apresentaram esse argumento. Outra consideração a ser feita é: se eles realmente não sabem utilizar essa ferramenta, por que não admitir e buscar o aprendizado? E mais: O que é capaz de motivar nossos jovens? E por quanto tempo?

- "Não sou bom com compromissos"

Identificamos isso com os alunos do grupo focal, quando, em elaboração de matérias para o blog, demonstravam angústia e incertezas, e que por MSN questionavam o professor se estava bom, necessitando de constante afirmação para efetivar suas propostas. Constatamos que, com o desenvolver das atividades e o incentivo da professora/pesquisadora, os alunos produtores do blog ganharam confiança e começaram a ser mais autônomos, chegando inclusive a proporem uma pesquisa sobre o aborto e irem até um shopping da cidade para realizarem as gravações de entrevistas.

Acreditamos que o trabalho conjunto e autônomo dos alunos aliados ao uso das tecnologias colaborou para que o protagonismo dos alunos se desenvolvesse. De acordo com Fey, "o uso da tecnologia potencializa a dialogicidade e a mediação, na medida em que muda o conceito de tempo e espaço". (2011, p.4).

Outro fator que destacamos como marco do protagonismo manifesto pode ser entendido ao analisarmos as respostas dos alunos produtores do blog ao serem questionados sobre o que os motivava a continuar no projeto enquanto outros desistiram.

Respostas:

- "[...] tem várias coisas, primeiro a gente se comprometeu desde o início, a gente veio a todas as reuniões, a gente ficou sabendo, a gente foi procurar, e pular fora assim no meio do nada é meio suada."

- "poxa é legal falar aqui e no futuro, falar que ajudei a construir um blog no colégio, que fiz alguma coisa útil no colégio."

- "Gente, tô me achando, se eu digitar meu nome no Google ele aparece em várias páginas”. 
O desafio da atividade proposta, a satisfação pessoal, o incentivo dos colegas e do professor e a possibilidade de ser atuante, certamente são fatores que colaboraram para motivar e possibilitar o protagonismo desses alunos. Com isso, conseguiram produzir o blog $\mathrm{CMBio}$ destinado a várias temáticas relacionadas à Biologia e o divulgaram nas redes sociais. Para isso, fizeram um vídeo locado no YouTube, Postaram ainda chamadas e enquetes no Facebook, Twitter e até no Orkut.

\subsection{Interação}

A análise dos dados dessa temática foi realizada sob a perspectiva dos processos interacionais ocorridos entre os usuários do blog e os seus produtores; entre os alunos do grupo focal (nativos digitais) e a professora/pesquisadora (imigrante digital) e entre os demais alunos e as NTICE utilizadas (blog e outras redes sociais relacionadas).

Desde o início da criação do blog, intitulado pelos alunos por meio de enquete, de CMBio, não pretendíamos utilizá-lo como recurso pedagógico que implicasse em uma ferramenta de cobrança de atividades dos alunos e sim que eles o buscassem e dele usufruíssem por interesse nas informações. Esperávamos ainda que, ao interagirem com as informações e com os colegas por meio dos comentários, eles se sentissem estimulados a apresentar sugestões, tirando dúvidas, acrescentando informações, enfim, contribuindo para a sua aprendizagem e a dos demais usuários.

Dos 129 alunos que responderam a pergunta: Vocês chegaram a usar o blog CMBio? 123 disseram que sim, 3 alegaram que desconheciam o endereço, 1 não teve interesse e o outro estava sem internet. Em um período de aproximadamente 11 meses o blog teve mais de 11 mil visualizações, inclusive no período de férias escolares.

Com relação ao uso das ferramentas para postar comentários identificamos que houve pouca troca de informações entre os usuários, apenas 5, alguns no blog e outros na página do Facebook CMBIO, as quais pouco ou nada contribuíram para os propósitos esperados. Essa percepção converge com os relatos de Boeira (2011) a qual, ao analisar a linguagem empregada pelos alunos e professores em blogs educativos, concluiu que essas interações só ocorriam quando o professor estimulava por meio de tarefas a serem realizadas, não contribuindo para a autonomia e iniciativa dos educandos. Essa autora atribui esse comportamento a certa acomodação dos alunos em decorrência de uma vivência de aulas tradicionais, nas quais os alunos só fazem o que lhes é cobrado.

As justificativas dos alunos para postarem comentários ou não foi alvo de uma das perguntas do questionário 2 , as quais foram categorizadas e revelaram como motivações a falta de interesse $(23,6 \%)$; a não percepção de aplicabilidade $(18,1 \%)$; disponibilidade de tempo $(10,2 \%)$; desconforto com a opinião pública $(9,4 \%)$ e falta de domínio técnico $(2,4 \%)$. Houve ainda os que disseram que até tiveram interesse, mas não o fizeram $(6,3 \%)$. Novamente o desinteresse em não responderem a questões abertas aparece, pois $26 \%$ dos alunos não responderam por que não comentaram as publicações no blog.

Essa falta de interesse em postar comentários pode estar relacionada à falta de envolvimento direto desses alunos no processo de construção do blog, uma vez que somente 8 alunos se envolveram diretamente nessa atividade. Além disso, esse tipo de postagem em princípio exige do leitor comentários que demonstrem conhecimento sobre o assunto ou a disposição em assumir diante do grupo que desconhece a informação ou que tem dúvidas.

Discutimos esse assunto com os alunos do grupo focal na tentativa de melhor compreendermos esse fenômeno e obtivemos as seguintes respostas: 
- "Eu acho que o pessoal não quer perder tempo, porque acham que é perda de tempo e não fazem."

- "Acho que eles têm até ideias, mas eles ficam vendo vídeos, ficam no batepapo, ou participam como seguidores do blog, alguma coisa assim. Aí não fazem comentários”.

- "Pode ser por vergonha".

Ao perguntamos o que poderia ser feito para estimular os colegas a participarem, os alunos prontamente citaram várias possibilidades, tais como: colocar jogos, ir de sala em sala avisando, mandar mensagens via redes sociais para os colegas. Mas o que nos surpreendeu foi o seguinte comentário:

- “Seria mais prático chegar à sala e obrigar todo mundo a ler”.

Que foi prontamente repudiado por outro, que disse:

- “Não, nem todos vão querer, não é obrigado a entrar no blog”.

Outro:

- “Dar um ponto na média para quem comentar no blog”.

Questionados se achavam que os alunos só participariam se valesse nota, a maioria concordou e uma aluna acrescentou:

- "Depende do que seja, tipo, não sei o que acontece, sempre tem que ter alguma coisa em troca, na sociedade e hoje tudo é troca, ou seja, o que tem que acontecer é o pessoal ter na cabeça o que vai ganhar depois. O que eu estranho nessa história é que todo mundo fica na internet, entrar no blog é tão fácil. Tem coisas nada a ver no facebook que tem, sei lá, um monte de comentários.”

Esse comentário demonstra de certa forma uma frustração e um desabafo da aluna, que ao assumir o compromisso com o grupo e querer ver resultados, aponta como solução recursos vivenciados em um processo de ensino que prima pela imposição e não pelo diálogo.

Contudo, apesar da pouca interação dos alunos por meio de mensagens eletrônicas percebemos que a mesma ocorreu se considerarmos o entrosamento e a interação percebidos entre os alunos do grupo produtor do blog e destes com essa professora/pesquisadora. Acreditamos que isso ocorreu em virtude dos membros desse grupo terem se relacionado mais proximamente e compartilharem uma meta em comum, previamente discutida e opinada por eles. A liberdade e a confiança depositada nesse grupo permitiram que esses alunos se sentissem mais à vontade, autônomos para questionar, ensinar e aprender. Abaixo retratamos um desses momentos:

- "Profa: Alguém sabe entrar aqui agora? Esse aqui é criar, mas como eu entro na página de criação, eu ô tentando, naquele endereço mesmo" (Diálogo sobre postagem no blog).

- "Aluna: Bota no Google bioblogcmb, que ele pode não ter ativado".

- "Aluna: Tem que ativar." (Nesse momento a aluna assume o comando do computador e mostra como fazer)

- "Prof ${ }^{\mathrm{a}}::$ Entendi, então tá [...] o que vocês acham?"

Vygotsky (2002), ao se referir ao desenvolvimento cognitivo, descreve a linguagem como instrumento mediador, a qual com o advento das tecnologias ganhou uma nova dimensão. Isso nos leva a refletir: Quem nunca aprendeu algo com um jogo, um vídeo, em um tutorial da internet ou mesmo um simulador? O que seria dos inúmeros cursos de Educação a Distância se não houvesse interação mediada pelos educadores on line, pelos colegas e mesmo pelo próprio computador e suas interfaces? De acordo com Fey, "o uso da tecnologia potencializa a dialogicidade e a mediação, na medida em que muda o conceito de tempo e espaço" (2011, p.4). 
Concordamos com Boeira (2011) no que tange à avaliação do blog como ferramenta pedagógica em relação à aprendizagem dos alunos, de acordo com ela "a aprendizagem dos estudantes não pode ser reduzida unicamente ao registro de enunciados no blog [...] eles podem utilizar a fala social para trocar enunciados com os colegas e com o professor sobre o conteúdo estudado." (Boeira, 2011, p.158).

\subsection{Concepções dos alunos sobre o blog CMBio}

Além das contribuições já destacadas neste tópico nos atentamos em descrever como os alunos avaliaram e se apropriaram do blog CMBio. Dos 127 alunos respondentes a pergunta: O blog contribuiu para a sua aprendizagem? 123 alunos (98\%) responderam que sim e o avaliaram favoravelmente, considerando os conceitos excelente, muito bom e bom, como pode ser conferido na figura 1 .

\section{Avaliação do blog/CMBIO}

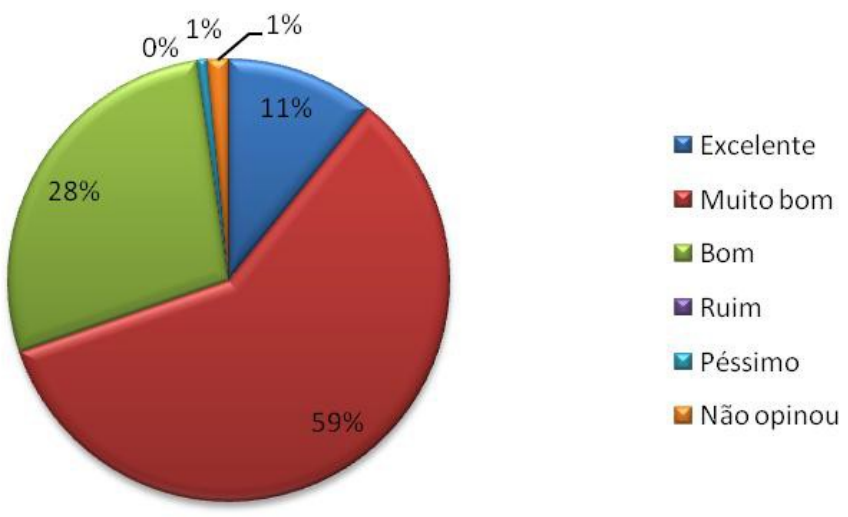

Figura 1 - Avaliação dos alunos sobre o blog CMBio Fonte: Nascimento, 2012.

Eles também apontaram que a abordagem de informações relacionadas à Biologia por meio do blog CMBio, lhes proporcionou novos conhecimentos com $81.9 \%$ das respostas, sendo que $17,3 \%$ descreveram que as postagens lhes possibilitou aprofundar seus conhecimentos. As curiosidades apresentadas também foram mencionadas neste item por $22 \%$ dos alunos.

Por meio das visualizações de página do blog cujos registros puderam ser resgatados por meio das informações estatísticas oferecidas pelo software percebemos que os slides das aulas elaborados pela professora eram os mais procurados, o que nos leva a acreditar que embora os alunos tivessem informações por meio do livro didático e até mesmo pela internet eles queriam fontes seguras de informação e de forma mais objetiva. Outra página bastante visualizada foi a principal onde constavam as matérias elaboradas pelos alunos contendo informações variadas. As vídeo-aulas selecionadas da internet e postadas pelos alunos, com as devidas referências, também tiveram grande aceitação.

Destacamos que esse ambiente serviu também de mural virtual para as atividades desenvolvidas em sala, possibilitando que alunos mesmo não participando diretamente da produção pudessem de alguma forma se sentir prestigiados no mesmo. Além disso, alunos de outras turmas e outros públicos do blog podem visualizar suas produções, compartilhar informações e conhecimento, bem como servir de parâmetro 
para a realização de atividades do gênero. Essa diversidade agradou os alunos que o consideraram como colaborador da sua aprendizagem, trazendo-lhes também novos conhecimentos. De maneira geral percebeu-se que todas as páginas foram visualizadas e foram mencionadas pelos alunos nos questionários.

\section{Conclusões}

A sociedade cada vez mais tecnológica exige uma formação cidadã, a qual envolve o desenvolvimento de habilidades e competências voltadas à leitura crítica dos fatos, a tomada consciente de decisões, o trabalho em equipe e a capacidade de constante (re) aprendizagem.

Acompanhando o contexto da sociedade em rede, o blog demonstrou ser uma ferramenta midiática eficaz na divulgação de materiais de diferentes gêneros textuais, incluindo vídeos, imagens, músicas e textos diversificados. Sendo uma ferramenta que possibilitou o professor a „falar a mesma linguagem dos alunos, mais objetiva, visual e sintética, esse espaço virtual foi utilizado para disponibilizar os slides utilizados nas aulas de Biologia, o que lhes permitiu explorá-lo a qualquer tempo e fora da escola, respeitando os diferentes interesses e ritmos.

A participação ativa dos alunos produtores do CMBio colaborou para o desenvolvimento do protagonismo juvenil, uma vez que ao assumir o papel de protagonista na produção e divulgação da informação por meio do blog, os alunos sentiram-se valorizados e motivados pelo reconhecimento não somente do professor e dos colegas, mas também pelo compromisso assumido e pela satisfação em ver seus trabalhos divulgados na internet.

Como referenciado por Paulo Freire (1988), a pessoa, quando se percebe sujeito de sua própria história, é capaz de traçar metas e estratégias para alcançar seus objetivos, por meio do pensar e do agir, calcados em reflexão e diálogo com os outros e com o mundo.

Para isso foi fundamental o envolvimento e a interação estabelecida entre os alunos e destes com o professor, que, ao assumir para si e para eles que tinha o que ensinar, mas também muito que aprender, conseguiu estabelecer com eles um elo, propiciando um clima de confiança e estímulo. Como apontado por Paulo Freire (1988), o educador, ao valorizar o educando, é capaz de perceber a própria prática pedagógica como libertadora, que propicia o desenvolvimento da sua consciência crítica, seu caráter ético e transformador.

Nesse entendimento o sistema educacional precisa considerar que os nativos digitais estão inseridos em um ambiente sócio-histórico tecnológico no qual predominam as relações em rede. Um processo educativo que privilegia o individualismo e a competição colabora para a ansiedade e dispersão desses jovens, sendo necessário reconhecer que "eles funcionam melhor quando em rede" (Prensky, 2001).

Para Prensky (2001), os alunos nativos digitais fazem coisas diferentes ao mesmo tempo, prospera na gratificação instantânea e em recompensas frequentes, o que justifica o desejo por um ensino que lhes proporcione uma participação mais efetiva e interativa, o que não deve ser confundido com acúmulo de atividades e sim que promovam seu envolvimento no processo ensino-aprendizagem, fazendo-os ver e ouvir.

\section{Referências Bibliográficas}

BARDIN, L. Análise de conteúdo. São Paulo: Edições Persona, 2011. 
BOEIRA, A. F. A linguagem em blog educativo e o processo de aprendizagem. Universidade de Caxias do Sul, Pós-graduação em Educação, Caxias do Sul, 2011.

COSTA, R. E. da. Alfabetização em Informação: Um estudo de caso sobre o perfil do professor mediador da Escola Digital Integrada (EDI). Brasília: UnB, 2010. Dissertação (Mestrado) - Departamento de Ciência da Informação e Documentação - CID, Universidade de Brasília, Brasília, 2010.

FEY, A. F. A linguagem na interação professor-aluno na era digital: considerações teóricas. Revista Tecnologias na Educação, ano 3, n.1, jul. 2011.

FREIRE, P. Pedagogia do oprimido. 18. ed., Rio de Janeiro: Paz e Terra, 1988.

GOMES DA COSTA, A. C. A implementação das medidas socioeducativas. Belo Horizonte, 1996.

LÉVY, P. Cibercutura. São Paulo: Editora 34, 1999.

A inteligência coletiva: por uma antropologia do ciberespaço. Trad. Luiz Paulo Rouanet. 2. ed. São Paulo: Loyola, 1999 b.

MORAN, J. M. Ensino e aprendizagem inovadores com tecnologias. Revista Informática na Educação: Teoria \& Prática. Programa de Pós-Graduação em Informática na Educação. Porto Alegre, v. 3, n.1, UFRGS, p. 137-144, set. 2000.

NASCIMENTO, L. M. C. T. Blogs e outras redes sociais no Ensino de Biologia: o aluno como produtor e divulgador. 2012. 173f. Dissertação (Mestrado em Ensino de Ciências) - Instituto de Física, Instituto de Química e Instituto de Ciências Biológicas, Universidade de Brasília, Brasília-DF, 2012.

PRENSKY, M. Digital Natives, Digital Immigrants. Disponível em: $<$ http://www. marcprensky.com/writing/, texto publicado na sua primeira versão em 2001>. Acesso em: 10 mar. 2014.

PRIMO, A. F. T.; SMANIOTTO, A. M. R. Blogs como espaços de conversação: interações conversacionais na comunidade de blogs. Insanus e Compos, v. 1, n. 5, p. 121, 2006.

RECUERO. R. Cinco pontos sobre as redes sociais na internet- parte 1 e 2. 2009. Disponível em:

$<$ :http://www.jornalistasdaweb.com.br/index.php?pag=displayConteudo\&idConteudo=3 964>. Acesso em: 04 abr.2014.

VYGOTSKY, L. S. Pensamento e linguagem. 2002. Edição eletrônica: Ed Ridendo Castigat Mores. Disponível em: $<$ http://www.ebooksbrasil.org/eLibris/vigo.html $>$. Acesso em: 06 jan. 2014. 